\title{
Mutations in the WFS1 gene are a frequent cause of autosomal dominant nonsyndromic low-frequency hearing loss in Japanese
}

\author{
Hisakuni Fukuoka $\cdot$ Yukihiko Kanda $\cdot$ \\ Shuji Ohta $\cdot$ Shin-ichi Usami
}

Received: 14 January 2007 / Accepted: 27 March 2007/Published online: 11 May 2007

(C) The Japan Society of Human Genetics and Springer 2007

\begin{abstract}
Mutations in WFS1 are reported to be responsible for two conditions with distinct phenotypes; DFNA6/ $14 / 38$ and autosomal recessive Wolfram syndrome. They differ in their associated symptoms and inheritance mode, and although their most common clinical symptom is hearing loss, it is of different types. While DNFA6/14/38 is characterized by low frequency sensorineural hearing loss (LFSNHL), in contrast, Wolfram syndrome is associated with various hearing severities ranging from normal to profound hearing loss that is dissimilar to LFSNHL (Pennings et al. 2002). To confirm whether within non-syndromic hearing loss patients WFS1 mutations are found restrictively in patients with LFSNHL and to summarize the mutation spectrum of WFSI found in Japanese, we screened 206 Japanese autosomal dominant and 64 autosomal recessive (sporadic) non-syndromic hearing loss probands with various severities of hearing loss. We found three independent autosomal dominant families associated with two different WFS1 mutations, A716T and E864K, previously detected in families with European ancestry. Identification of the same mutations in independent families with different racial backgrounds suggests that both
\end{abstract}

H. Fukuoka $\cdot$ S. Usami $(\bowtie)$

Department of Otorhinolaryngology,

Shinshu University School of Medicine,

3-1-1 Asahi, Matsumoto 390-8621, Japan

e-mail: usami@hsp.md.shinshu-u.ac.jp

Y. Kanda

Kanda ENT Clinic, 4-25 Wakakusa-cho,

Nagasaki 852-8023, Japan

\section{S. Ohta}

Aomori Prefectural Hospital,

2-1-1 Higashi-Tsukurimichi,

Aomori 030-8553, Japan sites are likely to be mutational hot spots. All three families with WFS1 mutations in this study showed a similar phenotype, LFSNHL, as in previous reports. In this study, onethird (three out of nine) autosomal dominant LFSNHL families had mutations in the WFS1 gene, indicating that in non-syndromic hearing loss WFSI is restrictively and commonly found within autosomal dominant LFSNHL families.

Keywords WSF1 · Low-frequency hearing loss · DFNA6/14/38

\section{Introduction}

WFS1 is a gene encoding an 890 amino-acid glycoprotein (wolframin), predominantly localized in the endoplasmic reticulum. Mutations in WFS1 are reported to be responsible for both non-syndromic and syndromic forms of hearing loss: autosomal dominant low-frequency sensorineural hearing loss (LFSNHL) DFNA6/14/38, as well as autosomal recessive Wolfram syndrome. Both conditions are distinct with regard to phenotype, not only in associated symptoms and inheritance mode, but also in their mutual clinical symptom of hearing loss, which is manifested by different types. LFSNHL DFNA6/14/38 is a rare, but clearly differentiated type of hearing loss affecting the low frequencies $(2,000 \mathrm{~Hz}$ and below) that worsens over time, but does not progress to profound deafness. Wolfram syndrome is characterized by diabetes mellitus, diabetes insipidus, optic atrophy (Strom et al. 1998; Inoue et al. 1998) and normal or high/all frequency hearing loss with various hearing severities ranging from mild to profound (Pennings et al. 2004). Since WFS1 mutations have been found in various types of hearing loss, it was an interesting 
question whether WFS1 mutations could be found in nonsyndromic hearing loss patients with other than LFSNHL, but there had been no reports of mutation screening for various phenotypes of hearing.

Twenty-six heterozygous WFS1 mutations for non-syndromic hearing loss and 110 WFS1 mutations for Wolfram syndrome have been identified. Mutation spectrums of deafness genes, including GJB2 and SLC26A4, have been shown to be dependent on ethnic background (Ohtsuka et al. 2003; Tsukamoto et al. 2003), and therefore whether there is a unique WFS1 mutation spectrum in Japanese (most probably representative of other Asian populations) was also of interest.

The present study was carried out to (1) confirm the phenotype (whether within non-syndromic hearing loss patients WFS1 mutations are found restrictively in those with LFSNHL) and (2) summarize the mutation spectrum of WFS1 found in Japanese. To do so, we screened 206 Japanese autosomal dominant and 64 autosomal recessive (sporadic) non-syndromic hearing loss probands with various severities of hearing loss.

\section{Materials and methods}

\section{Subjects}

Two-hundred and six Japanese autosomal dominant (AD; with two or more generations affected) and 64 autosomal recessive (AR; normal hearing parents and more than two affected siblings or recessive compatible sporadic cases) sensorineural hearing loss patients were screened for mutations in the WFS1 gene. All probands were from independent families, and none had any other associated neurological signs, visual dysfunction or diabetes mellitus. Severity of hearing loss was classified by a pure-tone average over 500, 1,000, 2,000 and 4,000 Hz in the better hearing ears as follows: normal hearing, $<20 \mathrm{~dB}$; mild hearing loss, 21-40 dB; moderate hearing loss, 41-70 dB; severe hearing loss, 71-95 dB; and profound hearing loss, greater than $95 \mathrm{~dB}$ (GENDEAF 2004). The severity of hearing loss was classified from normal to profound: normal (only limited frequencies involved) in 12/0 patients $(<20 \mathrm{~dB})$, mild $(21-40 \mathrm{~dB})$ in $43 / 12(21 / 19 \%)$, moderate $(41-70 \mathrm{~dB})$ in $96 / 16(47 / 25 \%)$, severe $(71-95 \mathrm{~dB})$ in $32 / 9$ $(16 / 14 \%)$ and profound $(>95 \mathrm{~dB})$ in $23 / 27$ (11/42\%) (dominant/recessive respectively). The age of onset varied from congenital to 60/50 years (dominant/recessive respectively). The type of hearing loss was low frequency (2,000 $\mathrm{Hz}$ and below) involved in $9 / 3$ patients (4/5\%), high frequency $(2,000 \mathrm{~Hz}$ and above) involved in $14 / 12$ patients $(7 / 19 \%)$, and all frequencies involved in $183 / 49$ patients $(89 / 76 \%)$ (dominant/recessive, respectively).
The control group consisted of 86 unrelated Japanese individuals with normal hearing evaluated by auditory testing. All subjects gave prior informed consent for participation in the project, and the Ethical Committee of Shinshu University approved the study.

Mutation analysis

All eight exons and flanking intronic sequences except for exon 1 of the WFS1 gene were amplified by polymerase chain reaction PCR. Primers were designed to flank all of the exon-intron boundaries through use of the Primer3 webbased server (http://www-genome.wi.mi.edu/cgi-bin/primer/primer3_www.cgi). Each genomic DNA sample (40 ng) was amplified using Ex-Taq polymerase (Takara) for $5 \mathrm{~min}$ at $95^{\circ} \mathrm{C}$, followed by 37 three-step cycles of $95^{\circ} \mathrm{C}$ for $30 \mathrm{~s}, 56-63^{\circ} \mathrm{C}$ for $30 \mathrm{~s}$ and $72^{\circ} \mathrm{C}$ for $1.5 \mathrm{~min}$, with a final extension at $72^{\circ} \mathrm{C}$ for $10 \mathrm{~min}$, ending with a holding period at $4^{\circ} \mathrm{C}$ in a Perkin-Elmer thermal cycler. The PCR products varied in size at about 200-700 bp, and they were treated with $0.1 \mu \mathrm{l}$ exonuclease I (Amersham) and $1 \mu \mathrm{l}$ shrimp alkaline phosphatase (Amersham) and by incubation at $37^{\circ} \mathrm{C}$ for $30 \mathrm{~min}$, and inactivation at $80^{\circ} \mathrm{C}$ for $15 \mathrm{~min}$. After the products were purified, we performed standard cycle sequencing reaction with ABI Big Dye terminators in an ABI 3100 autosequencer (Applied Biosystems).

\section{Results}

Direct DNA sequencing identified two disease-causing mutations from AD families (Fig. 1), however no mutations were found in AR families. Twenty-eight polymorphisms were found among the studied subjects (Table 1). Family \#1 had a heterozygous $\mathrm{G} \rightarrow$ A transition at nucleotide 2,146 in exon 8, which results in an alanine-to-threonine substitution at codon 716 (A716T). Families \#2 and \#3 had a heterozygous $\mathrm{G} \rightarrow \mathrm{A}$ transition at nucleotide 2,590 in exon 8 , which results in a glutamic acid-to-lysine substitution at codon 864 (E864K). Genetic analysis showed cosegregation of E864K with LFSNHL in the family members available to be examined. In contrast, none of the 86 normal controls had these mutations. All of the patients with WFS1 mutations showed dominant inherited LFSNHL, and mutations were not found in dominant families with other types of hearing loss or recessive/sporadic families. Onethird (three out of nine) autosomal dominant LFSNHL families had mutations in the WFS1 gene.

\section{Discussion}

We found three independent autosomal dominant families associated with two different WFS1 mutations. All patients 
Fig. 1 Pedigrees of three families and individual sequence summaries.

Overlapped audiogram of nine subjects with WFS1 mutations showing low-frequency hearing loss
$\# 1$

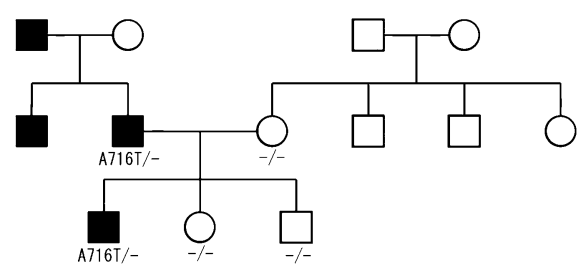

\#2

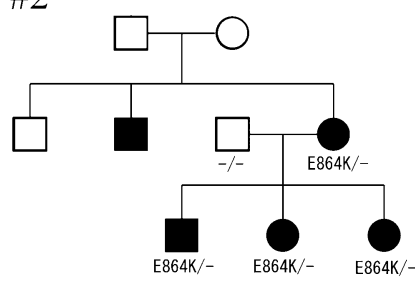

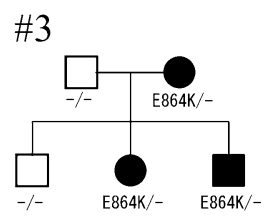

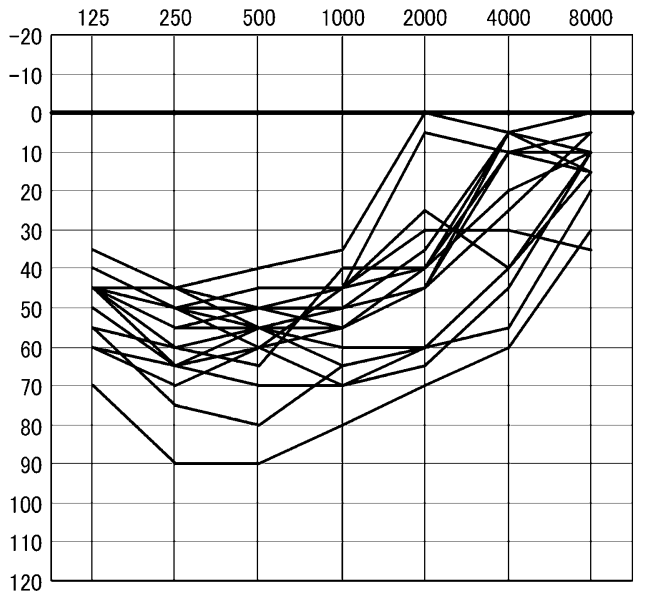

showed LFSNHL as previously reported in DFNA6/14/38 (Bespalova et al. 2001; Young et al. 2001; Eiberg et al. 2006). WFS1 mutations were not found in recessive families (even in the patients with lower frequency involved hearing loss), nor in other types of hearing loss, indicating that in non-syndromic form of hearing loss they can be found only in dominant families with LFSNHL. Despite the recent considerable advances in the discovery of deafness genes, clinical application still entails difficulties because of the genetic heterogeneity of deafness. Although nearly 100 genes are estimated to be responsible for hereditary hearing loss (Morton 1991), in general, many may cause similar phenotypes without any abnormality other than hearing loss. However, this particular type of hearing loss (LFSNHL) can be easily distinguished from others by audiogram. Attention should be paid to this when performing genetic testing, and WSF 1 should be the first gene to be screened for this category of patients. In addition, it must be remembered that the newborn hearing screening methods that are commonly used do not detect hearing loss that affects frequencies below $2,000 \mathrm{~Hz}$, requiring children at risk to receive special monitoring. LFSNHL is usually diagnosed by the age of 10 years and thereafter gradually progresses over a long period. Quite often young patients with LFSNHL show no symptoms and therefore do not use hearing aids, but in later life they may develop high-frequency loss, affecting speech perception. Routine monitoring has often not been performed even for children in families with a strong history of dominant LFSNHL. In the subjects of this study, hearing loss was noticed between 5 and 14 years old (mean: 10 years old), and three of nine patients used hearing aids. In DNFA6/14/ 38 there is no or only mild progression of hearing loss. Some patients have also reported tinnitus, but none reported vertigo or dizziness (Young et al. 2001; Lesperance et al. 2003; Pennings et al. 2003). In the present study, two out of nine patients noticed tinnitus, but none had progression of hearing loss or vertigo, in line with the previously reported phenotype.

In the present study, two mutations, A716T and E864K, previously reported in families with European ancestry, were found in three Japanese families. Until now, 26 WFS 1 mutations have been reported to be associated with DFNA6/ $14 / 38$ (Table 2), and this is the first example of WFS1 mutations found across different racial backgrounds. A similar presumed hot spot in a deafness gene found across different ethnicities by haplotype analysis is the $K C N Q 4$ missense mutation, W276S (van Camp et al. 2002).

The A716T mutation has been reported to be associated with six independent families of different racial backgrounds, including the present family, suggesting that it is likely to be a hot spot rather than due to a founder effect. Also E864K, found in two independent Japanese families in this study, has recently been reported in a family with European ancestry, indicating that this mutational site is also a possible hot spot. 
Table 1 Polymorphisms detected in the coding region of WFS1

\begin{tabular}{|c|c|c|c|c|c|c|}
\hline \multirow[t]{2}{*}{ Codon } & \multirow[t]{2}{*}{ Exon } & \multirow[t]{2}{*}{ Nucleotide change } & \multicolumn{2}{|c|}{ Patients } & \multirow[t]{2}{*}{ Controls } & \multirow[t]{2}{*}{ Reference } \\
\hline & & & $\mathrm{AD}$ & $\mathrm{AR}$ & & \\
\hline Q14R & E-2 & c. $41 \mathrm{~A}>\mathrm{G}$ & 2 & 1 & 1 & Kawamoto et al. (2004) \\
\hline $\mathrm{P} 44 \mathrm{P}$ & E-2 & c. $132 \mathrm{C}>\mathrm{T}$ & 1 & 0 & 0 & The present study \\
\hline A130A & E-4 & c. $390 \mathrm{G}>\mathrm{A}$ & 3 & 0 & 1 & The present study \\
\hline A150V & E-4 & c. $449 \mathrm{C}>\mathrm{T}$ & 4 & 0 & 2 & The present study \\
\hline $\mathrm{T} 170 \mathrm{~T}$ & E-6 & c. $510 \mathrm{C}>\mathrm{G}$ & 2 & 0 & 0 & Kawamoto et al. (2004) \\
\hline A326S & E-8 & c. $976 \mathrm{G}>\mathrm{T}$ & 1 & 0 & 0 & The present study \\
\hline D339A & E-8 & c. $1015 \mathrm{G}>\mathrm{A}$ & 1 & 0 & 0 & The present study \\
\hline $\mathrm{A} 342 \mathrm{~T}$ & E-8 & c. $1026 \mathrm{G}>\mathrm{A}$ & 1 & 0 & 0 & The present study \\
\hline $\mathrm{T} 378 \mathrm{~T}$ & E-8 & c. $1134 \mathrm{C}>\mathrm{A}$ & 1 & 0 & 2 & Crawford et al. (2002) \\
\hline E385E & E-8 & c. $1155 \mathrm{G}>\mathrm{A}$ & 1 & 0 & 2 & The present study \\
\hline E391E & E-8 & c. $1173 \mathrm{G}>\mathrm{A}$ & 1 & 0 & 2 & The present study \\
\hline V412L & E-8 & c. $1234 \mathrm{G}>\mathrm{C}$ & 1 & 1 & 6 & Kawamoto et al. (2004) \\
\hline V412A & E-8 & c. $1235 \mathrm{~T}>\mathrm{C}$ & 2 & 5 & 0 & Kawamoto et al. (2004) \\
\hline $\mathrm{I} 421 \mathrm{~T}$ & E-8 & c. $1263 \mathrm{C}>\mathrm{G}$ & 1 & 0 & 0 & The present study \\
\hline $\mathrm{C} 426 \mathrm{~S}$ & E-8 & c. $1277 \mathrm{G}>\mathrm{C}$ & 1 & 0 & 0 & The present study \\
\hline A450A & E-8 & c. $1350 \mathrm{~A}>\mathrm{G}$ & 1 & 0 & 0 & The present study \\
\hline $\mathrm{R} 456 \mathrm{H}$ & E-8 & c. $1367 \mathrm{G}>\mathrm{A}$ & 53 & 11 & 22 & Inoue et al. (1998), and others \\
\hline $\mathrm{T} 461 \mathrm{~T}$ & E-8 & c. $1383 \mathrm{C}>\mathrm{T}$ & 1 & 0 & 0 & The present study \\
\hline G576S & E-8 & c. $1726 \mathrm{G}>\mathrm{A}$ & 57 & 17 & 30 & Awata et al. (2000), and others \\
\hline H611R & E-8 & c. $1832 \mathrm{~A}>\mathrm{G}$ & 57 & 12 & 25 & Inoue et al. (1998), and others \\
\hline C672C & E-8 & c. $2016 \mathrm{C}>\mathrm{G}$ & 1 & 0 & 0 & The present study \\
\hline I720V & E-8 & c. $2158 \mathrm{~A}>\mathrm{G}$ & 39 & 8 & 13 & Awata et al. (2000), and others \\
\hline E737K & E-8 & c. $2209 \mathrm{G}>\mathrm{A}$ & 23 & 6 & 6 & Ohtsuki et al. (2000), and others \\
\hline $\mathrm{K} 811 \mathrm{~K}$ & E-8 & c. $2433 \mathrm{G}>\mathrm{A}$ & 5 & 1 & 3 & Inoue et al. (1998), and others \\
\hline I823I & E-8 & c. $2469 \mathrm{C}>\mathrm{T}$ & 5 & 3 & 0 & Strom et al. (1998) \\
\hline K836K & E-8 & c. $2507 \mathrm{~A}>\mathrm{G}$ & 2 & 0 & 0 & The present study \\
\hline S855S & E-8 & c. $2565 \mathrm{G}>\mathrm{A}$ & 3 & 1 & 3 & Inoue et al. (1998), and others \\
\hline D866N & E-8 & c. $2596 \mathrm{G}>\mathrm{A}$ & 10 & 0 & 0 & Torres et al. (2001) \\
\hline
\end{tabular}

The present two mutations are situated in exon 8 , consistent with the tendency for mutations to be accumulated in that exon. Wolfram syndrome mutations are spread over the entire coding region and are typically inactivating, suggesting that a loss of function causes the disease phenotype. In contrast, only non-inactivating mutations have been found in DFNA6/14/38 families, and these mutations are mainly located in the $\mathrm{C}$-terminal protein domain.

Until now the function of the protein wolframin, the WFS1 gene product, has been unknown. In the brain, wolframin is restricted to certain populations of neurons, including the ventral cochlear nucleus and the inferior colliculus. However, analysis of the cochlear expression of wolframin using immunohistochemistry showed no differences in staining pattern or gradients of expression between the basal and apical parts of the cochlea (Cryns et al. 2003a). Wolframin is a membrane glycoprotein that is primarily localized in the endoplasmic reticulum, where it may serve as a calcium channel or regulator of calcium channel and is thought to be an integral, endoglycosidase H-sensitive membrane glycoprotein (Inoue et al. 1998; Takeda et al. 2001). Wolframin can be an integral, endoglycosidase $\mathrm{H}$-sensitive membrane glycoprotein that is localized primarily in the endoplasmic reticulum. This localization suggests that this protein plays a yet undefined role in membrane trafficking, protein processing and/or regulation of calcium homeostasis (Takeda et al. 2001). Additionally, in a recent study, it was suggested that ERstress and N-glycosylation play important roles in wolframin expression and stability (Yamaguchi et al. 2004; Yamada et al. 2006).

Wolfram syndrome is a rare autosomal recessive neurodegenerative disorder of juvenile onset, also known as DIDMOAD (diabetes insipidus, diabetes mellitus, optic atrophy and deafness). Minimal diagnostic criteria are diabetes and optic atrophy unexplained by any other disease. Other less frequent features include psychiatric abnormalities, ataxia, urinary tract atony, limited joint 
Table 2 WFS1 gene mutations found in non-syndromic SNHL patients

\begin{tabular}{|c|c|c|c|c|}
\hline 1 & R161Q & E-5 & c. $482 \mathrm{G}>\mathrm{A}$ & Tranebjaerg et al. ${ }^{\mathrm{a}}$ \\
\hline \multirow[t]{2}{*}{2} & K193Q & E-5 & c. $577 \mathrm{~A}>\mathrm{C}$ & Cryns et al. (2002) \\
\hline & K193Q & E-5 & c. $577 \mathrm{~A}>\mathrm{C}$ & Smith et al. ${ }^{\mathrm{a}}$ \\
\hline 3 & $\mathrm{R} 457 \mathrm{~S}$ & E-8 & c. $1371 \mathrm{G}>\mathrm{T}$ & Smith et al. ${ }^{\mathrm{a}}$ \\
\hline 4 & M518I & E-8 & c. $1554 \mathrm{G}>\mathrm{A}$ & Smith et al. ${ }^{\mathrm{a}}$ \\
\hline 5 & L557F & E-8 & c. $1669 \mathrm{C}>\mathrm{T}$ & Smith et al. ${ }^{\mathrm{a}}$ \\
\hline 6 & A602V & E-8 & c. $1805 \mathrm{C}>\mathrm{T}$ & Smith et al. ${ }^{\mathrm{a}}$ \\
\hline 7 & V624A & E-8 & c. $1871 \mathrm{~T}>\mathrm{C}$ & Smith et al. ${ }^{\mathrm{a}}$ \\
\hline 8 & K634T & E-8 & c. $1901 \mathrm{~A}>\mathrm{C}$ & Komatsu et al. (2002) \\
\hline 9 & G674E & E-8 & c. $2021 \mathrm{G}>\mathrm{A}$ & Cryns et al. (2002) \\
\hline 10 & G674V & E-8 & c. $2021 \mathrm{G}>\mathrm{T}$ & Cryns et al. (2002) \\
\hline 11 & W678L & E-8 & c. $2033 \mathrm{G}>\mathrm{T}$ & Sivakumaran and Lesperance \\
\hline \multirow[t]{3}{*}{12} & T699M & E-8 & c. $2096 \mathrm{C}>\mathrm{T}$ & Bespalova et al. (2001) \\
\hline & T699M & E-8 & c. $2096 \mathrm{C}>\mathrm{T}$ & Cryns et al. (2002) \\
\hline & T699M & E-8 & c. $2096 \mathrm{C}>\mathrm{T}$ & Tranebjaerg et al. ${ }^{\mathrm{a}}$ \\
\hline 13 & $\mathrm{~K} 705 \mathrm{~N}$ & E-8 & c. $2115 \mathrm{G}>\mathrm{C}$ & Kunz et al. (2003) \\
\hline \multirow[t]{6}{*}{14} & A716T & E-8 & c. $2146 \mathrm{G}>\mathrm{A}$ & Bespalova et al. (2001) \\
\hline & A716T & E-8 & c. $2146 \mathrm{G}>\mathrm{A}$ & Bespalova et al. (2001) \\
\hline & A716T & E-8 & c. $2146 \mathrm{G}>\mathrm{A}$ & Young et al. (2001) \\
\hline & A716T & E-8 & c. $2146 \mathrm{G}>\mathrm{A}$ & Smith et al. ${ }^{\mathrm{a}}$ \\
\hline & A716T & E-8 & c. $2146 \mathrm{G}>\mathrm{A}$ & Sivakumaran and Lesperance ${ }^{a}$ \\
\hline & A716T & E-8 & c. $2146 \mathrm{G}>\mathrm{A}$ & The present study \\
\hline 15 & Idel767 & E-8 & c.2300_2302del & Cryns et al. (2002) \\
\hline 16 & $\mathrm{D} 771 \mathrm{H}$ & E-8 & c. $2311 \mathrm{G}>\mathrm{C}$ & Gurtler et al. (2005) \\
\hline 17 & V779M & E-8 & c. $2335 \mathrm{G}>\mathrm{A}$ & Bespalova et al. (2001) \\
\hline 18 & S807R & E-8 & c. $2419 \mathrm{~A}>\mathrm{C}$ & Cryns et al. (2002) \\
\hline \multirow[t]{3}{*}{19} & L829P & E-8 & c. $2486 \mathrm{~T}>\mathrm{C}$ & Bespalova et al. (2001) \\
\hline & L829P & E-8 & c. $2486 \mathrm{~T}>\mathrm{C}$ & Smith et al. ${ }^{\mathrm{a}}$ \\
\hline & L829P & E-8 & c. $2486 \mathrm{~T}>\mathrm{C}$ & Smith et al. ${ }^{\mathrm{a}}$ \\
\hline \multirow[t]{2}{*}{20} & G831D & E-8 & c. $2492 \mathrm{G}>\mathrm{A}$ & Bespalova et al. (2001) \\
\hline & G831D & E-8 & c. $2492 \mathrm{G}>\mathrm{A}$ & Cryns et al. (2002) \\
\hline 21 & A844T & E-8 & c. $2530 \mathrm{G}>\mathrm{A}$ & Noguchi et al. (2005) \\
\hline 22 & R859P & E-8 & c. $2576 \mathrm{G}>\mathrm{C}$ & Gurtler et al. (2005) \\
\hline \multirow[t]{3}{*}{23} & E864K & E-8 & c. $2590 \mathrm{G}>\mathrm{A}$ & Eiberg et al. (2006) \\
\hline & E864K & E-8 & c. $2590 \mathrm{G}>\mathrm{A}$ & The present study \\
\hline & E864K & E-8 & c. $2590 \mathrm{G}>\mathrm{A}$ & The present study \\
\hline
\end{tabular}

Three missense mutations, 2016G $>$ T, 2379G $>4 \mathrm{~A}$ and

$2766 \mathrm{G}>\mathrm{A}($ Liu et al. 2005) were omitted because the original data could not be accessed

${ }^{\text {a }}$ http://

www.khri.med.umich.edu/ research/lesperance_lab/ lfsnhl_sub.php
In the present study, various WFS1 sequence variants were found (Table 1). In the present patients, no apparent phenotype appeared to be associated with these single nucleotide polymorphisms, although several WFS1 sequence variants have previously been shown to be significantly associated with diabetes mellitus and psychiatric diseases (Cryns et al. 2003b). Additional genotype-phenotype correlation study will clarify the detailed phenotypic range caused by WFS1 mutations.

Acknowledgments We thank all the families that participated in the present project. We would also would like to thank Mr. S. Nishio and Ms. S. Matsuda for technical assistance, and Ms. A. C. AppleMathews for help in preparing the manuscript. This study was supported by a Health Sciences Research Grant (Research on Eye and 
Ear Science, Immunology, Allergy and Organ Transplantation) from the Ministry of Health and Welfare of Japan and by the Acute Profound Deafness Research Committee of the Ministry of Health and Welfare of Japan.

\section{References}

Bespalova IN, Van Camp G, Bom SJH, Brown DJ, Cryns K, DeWan AT, Erson AE, Flothmann K, Kunst HP, Kurnool P, Sivakumaran TA, Cremers CW, Leal SM, Burmeister M, Lesperance MM (2001) Mutations in the Wolfram syndrome 1 gene (WFS1) are a common cause of low frequency sensorineural hearing loss. Hum Mol Genet 10:2501-2508

Cryns K, Pfister M, Pennings RJE, Bom SJH, Flothmann K, Caethoven G, Kremer H, Schatteman I, Köln KA, Tóth T, Kupka S, Blin N, Nürnberg P, Thiele H, van de Heyning PH, Reardon W, Stephens D, Cremers CWRJ3, Smith RJH, Van Camp G (2002) Mutations in the WFS1 gene that cause lowfrequency sensorineural hearing loss are small non-inactivating mutations. Hum Genet 110:389-394

Cryns K, Thys S, Van Laer L, Oka Y, Pfister M, Van Nassauw L, Smith RJ, Timmermans JP, Van Camp G (2003a) The WFS1 gene, responsible for low frequency sensorineural hearing loss and Wolfram syndrome, is expressed in a variety of inner ear cells. Histochem Cell Biol 119(3):247-256

Cryns K, Sivakumaran TA, Van den Ouweland JM, Pennings RJ, Cremers CW, Flothmann K, Young TL, Smith RJ, Lesperance MM, Van Camp G (2003b) Mutational spectrum of the WFS1 gene in Wolfram syndrome, nonsyndromic hearing impairment, diabetes mellitus, and psychiatric disease. Hum Mutat 22(4):275-287

Eiberg H, Hansen L, Kjer B, Hansen T, Pedersen O, Bille M, Rosenberg T, Tranebjaerg L (2006) Autosomal dominant optic atrophy associated with hearing impairment and impaired glucose regulation caused by a missense mutation in the WFS1 gene. J Med Genet 43(5):435-440

GENDEAF (2004) European thematic network on genetic deafness. http://www.gendeaf.org

Gurtler N, Kim Y, Mhatre A, Schlegel C, Mathis A, Daniels R, Shelton C, Lalwani AK (2005) Two families with nonsyndromic low-frequency hearing loss harbor novel mutations in Wolfram syndrome gene 1. J Mol Med 83:553-560

Inoue $\mathrm{H}$, Tanizawa Y, Wasson J, Behn P, Kalidas K, Bernal-Mizrachi E, Mueckler M, Marshall H, Donis-Keller H, Crock P, Rogers D, Mikuni M, Kumashiro H, Higashi K, Sobue G, Oka Y, Permutt MA (1998) A gene encoding a transmembrane protein is mutated in patients with diabetes mellitus and optic atrophy (Wolfram syndrome). Nat Genet 20:143-148

Komatsu K, Nakamura N, Ghadami M, Matsumoto N, Kishino T, Ohta T, Niikawa N, Yoshiura K (2002) Confirmation of genetic homogeneity of nonsyndromic low-frequency sensorineural hearing loss by linkage analysis and a DFNA6/14 mutation in a Japanese family. J Hum Genet 47:395-399

Kunz J, Marquez-Klaka B, Uebe S, Volz-Peters A, Berger R, Rausch $P$ (2003) Identification of a novel mutation in WFS1 in a family affected by low-frequency hearing impairment. Mutat Res 525:121-124

Lesperance MM, Hall JW 3rd, San Agustin TB, Leal SM (2003) Mutations in the Wolfram syndrome type 1 gene (WFS1) define a clinical entity of dominant low-frequency sensorineural hearing loss. Arch Otolaryngol Head Neck Surg 129(4):405-406

Liu YH, Ke XM, Xiao SF (2005) Heterogenous mutations of Wolfram syndrome I gene responsible for low frequency nonsyndromic hearing loss. Zhonghua Er Bi Yan Hou Tou Jing Wai Ke Za Zhi 10:764-768

Morton NE (1991) Genetic epidemiology of hearing impairment. Ann N Y Acad Sci 630:16-31

Noguchi Y, Yashima T, Hatanaka A, Uzawa M, Yasunami M, Kimura A, Kitamura K (2005) A mutation in Wolfram syndrome type 1 gene in a Japanese family with autosomal dominant lowfrequency sensorineural hearing loss. Acta Otolaryngol 11:11891194

Ohtsuka A, Yuge I, Kimura S, Namba A, Abe S, Van Laer L, Van Camp G, Usami S (2003) GJB2 deafness gene shows a specific spectrum of mutations in Japan, including a frequent founder mutation. Hum Genet 112:329-333

Pennings RJ, Bom SJ, Cryns K, Flothmann K, Huygen PL, Kremer H, Van Camp G, Cremers CW (2003) Progression of low-frequency sensorineural hearing loss (DFNA6/14-WFS1). Arch Otolaryngol Head Neck Surg 129(4):421-426

Pennings RJ, Huygen PL, van den Ouweland JM, Cryns K, Dikkeschei LD, Van Camp G, Cremers CW (2004) Sex-related hearing impairment in Wolfram syndrome patients identified by inactivating WFS1 mutations. Audiol Neurootol 9(1):51-62

Strom TM, Hortnagel K, Hofmann S, Gekeler F, Scharfe C, Rabl W, Gerbitz KD, Meitinger T (1998) Diabetes insipidus, diabetes mellitus, optic atrophy and deafness (DIDMOAD) caused by mutations in a novel gene (wolframin) coding for a predicted transmembrane protein. Hum Mol Genet 7:2021-2028

Takeda K, Inoue H, Tanizawa Y, Matsuzaki Y, Oba J, Watanabe Y, Shinoda K, Oka Y (2001) WFS1 (Wolfram syndrome 1) gene product: predominant subcellular localization to endoplasmic reticulum in cultured cells and neuronal expression in rat brain. Hum Mol Genet 10(5):477-484

Tsukamoto K, Suzuki H, Harada D, Namba A, Abe S, Usami S (2003) Distribution and frequencies of PDS (SLC26A4) mutations in Pendred syndrome and nonsyndromic hearing loss associated with enlarged vestibular aqueduct: a unique spectrum of mutations in Japanese. Eur J Hum Genet 11:916-922

Van Camp G, Coucke PJ, Akita J, Fransen E, Abe S, De Leenheer EM, Huygen PL, Cremers CW, Usami S (2002) A mutational hot spot in the KCNQ4 gene responsible for autosomal dominant hearing impairment. Hum Mutat 20(1):15-19

Yamada T, Ishihara H, Tamura A, Takahashi R, Yamaguchi S, Takei D, Tokita A, Satake C, Tashiro F, Katagiri H, Aburatani H, Miyazaki J, Oka Y (2006) WFS1-deficiency increases endoplasmic reticulum stress, impairs cell cycle progression and triggers the apoptotic pathway specifically in pancreatic beta-cells. Hum Mol Genet 15(10):1600-1609

Yamaguchi S, Ishihara H, Tamura A, Yamada T, Takahashi R, Takei D, Katagiri H, Oka Y (2004) Endoplasmic reticulum stress and $\mathrm{N}$-glycosylation modulate expression of WFS1 protein. Biochem Biophys Res Commun 325(1):250-256

Young TL, Ives E, Lynch E, Person R, Snook S, MacLaren L, Cator T, Griffin A, Fernandez B, Lee MK, King MC (2001) Nonsyndromic progressive hearing loss DFNA38 is caused by heterozygous missense mutation in the Wolfram syndrome gene WFS1. Hum Mol Genet 10:2509-2514 